This item was submitted to Loughborough's Research Repository by the author.

Items in Figshare are protected by copyright, with all rights reserved, unless otherwise indicated.

\title{
An integrated information management model for proactive prevention of struck-by-falling-object accidents on construction sites
}

PLEASE CITE THE PUBLISHED VERSION

http://dx.doi.org/10.1016/j.autcon.2012.10.010

PUBLISHER

(C) Elsevier B.V.

VERSION

AM (Accepted Manuscript)

LICENCE

CC BY-NC-ND 4.0

\section{REPOSITORY RECORD}

Wu, Weiwei, Huanjia Yang, Qiming Li, and David A.S. Chew. 2019. "An Integrated Information Management Model for Proactive Prevention of Struck-by-falling-object Accidents on Construction Sites". figshare. https://hdl.handle.net/2134/14599. 
This item was submitted to Loughborough's Institutional Repository (https://dspace.lboro.ac.uk/) by the author and is made available under the following Creative Commons Licence conditions.

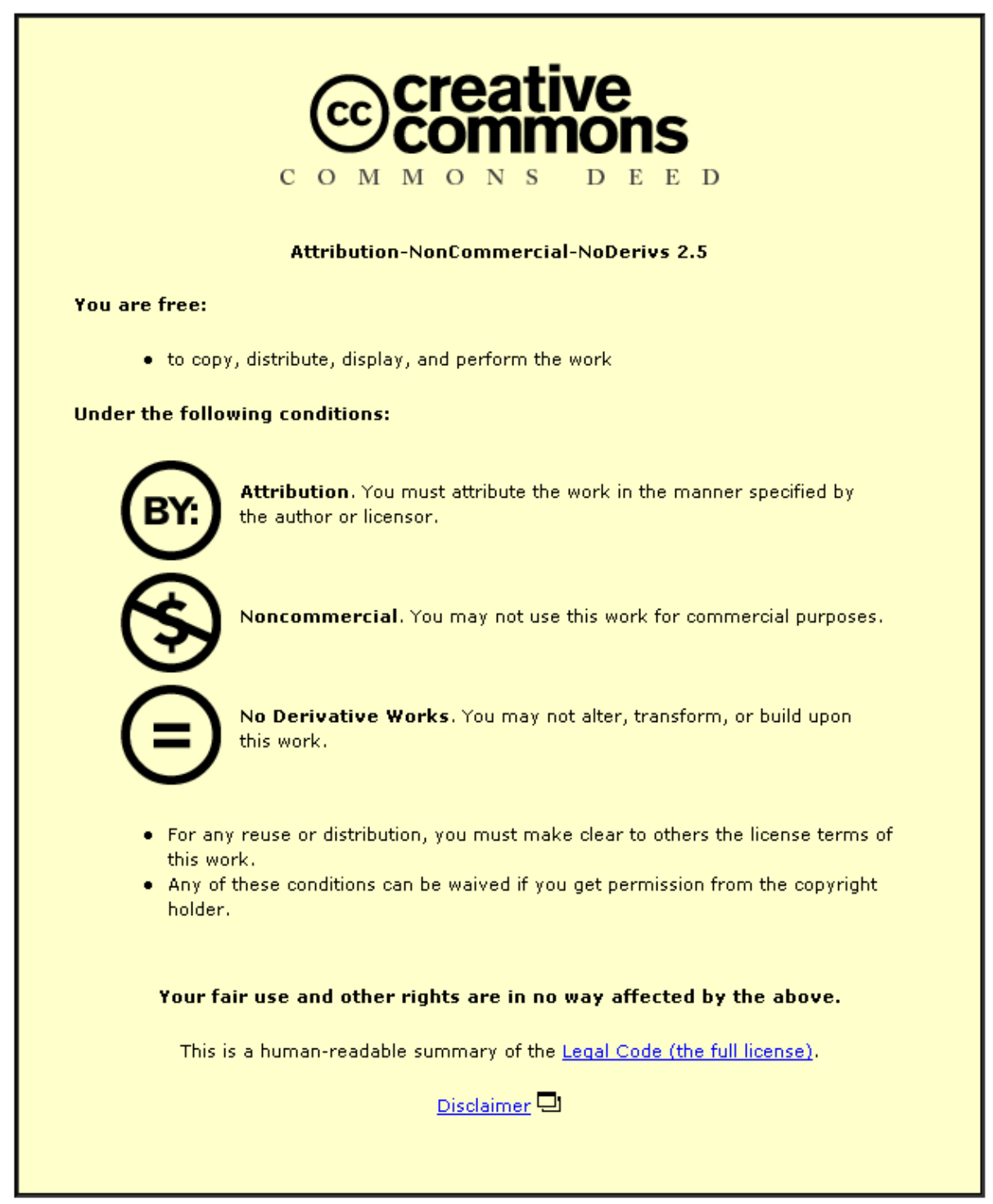

For the full text of this licence, please go to: http://creativecommons.org/licenses/by-nc-nd/2.5/ 


\title{
An Integrated Information Management System for Proactive Prevention of Struck-by-falling-object Accidents on Construction Sites
}

\author{
Weiwei $\mathrm{Wu}^{1 *}$, Huanjia Yang ${ }^{2}$, Qiming $\mathrm{Li}^{1}$, David A.S. Chew ${ }^{3}$
}

(1. Dept. of Construction Management and Real Estate, Southeast University, China;

2. School of Electronics and Computer Science, University of Southampton, UK;

3. School of Civil and Environmental Engineering, Nanyang Technological University, Singapore)

Abstract: The construction industry is the most hazardous industry in many countries. Struck-by-falling-object accidents are not paid adequate attention to though they are of great importance on construction sites. Great efforts have been made on the equipment involved accidents actuating automatic technology to improve construction safety in a proactive real-time mode. Nevertheless, little research has been done in both proactively preventive information requirement analysis of struck-by-falling-object accidents and automatic technological solutions to track crucial and controllable objects for proactive prevention. The objective of this paper is to analyze and verify the proactively preventive information requirement of struck-by-falling-object accidents and bring forward an integrated information management system using a Zigbee RFID sensor network to fulfil these requirements. First, the frequency of particular type of objects is analyzed based on vast historical accident cases. 499 cases have been investigated and categorized into 14 kinds and top three high frequency categories are beam and column, large mechanical

\footnotetext{
* Corresponding author. Dept. of Construction Management and Real Estate, Southeast University, China. Tel.: 13770581625; fax: 025-83793251. E-mail address: wuweiwei@seu.edu.cn (Dr. Weiwei Wu).
} 
equipment and pipe. In the meantime, tree trunk/branch, crane boom and steel beam are the top three high frequency kinds of involving objects. The most hazardous operation is pointed to be hoisting/lifting, which accounts for $41 \%$ of all cases. It is also argued that $66 \%$ of struck-by-falling-object accidents have the potential to be avoided. Then, this paper analyzed and verified the proactively preventive information requirement of struck-by-falling-object accidents and brought forward an integrated information management system. Furthermore, considering the crucial and controllable objects, an integrated information management system is proposed which employs ultrasonic for outdoor and indoor real-time location tracking, adopts RFID for access control as well as storage of safety information about workers, equipment and material, and wireless sensor network for data transmission. All system components are integrated into a Zigbee RFID sensor network architecture that features a relatively low cost and fast implementation with a pure wireless network backbone. The demonstration system based on the hybrid RFID sensor network architecture is then illustrated and discussed. This study would provide a possible approach for tracking struck-by-falling-object accidents based on real-time information for proactive prevention and could serve as a foundation for further study.

Keywords: Struck-by-falling-object, proactive prevention, integrated information management system, Zigbee RFID sensor network 


\section{Introduction}

The construction industry is the most hazardous industry in many countries (McCann, 2006; Thomas, 2006; Al-Humaidi1 and Tan, 2010). The most well known code categories of on-site accidents are falls, struck-by, caught in/between, and electric shock (Hinze et al., 1998). Struck-by accident is the second leading cause of death in construction, in which struck-by-equipment and struck-by-falling-object approximately account for 58\% and 42\% respectively (Wu et al., 2010b), after the accidents of falling from height (Chi et al., 2005; Aneziris et al., 2008).

Great efforts have been made on some specific accident safety hazards. Goh et al. (2010) evaluated the capacity of fall arrest energy absorbers in relation to the weight of heavy workers. Zeng et al. (2010) conducted an experiment to measure electric-field variation on simulated human-wrists. Teizer et al. (2010a) conducted a research to help identify the blind spots of equipment in order to quantify and protect the required safety zones for such equipment. Accidents of falling from height on construction sites have consistently been identified as of major importance, e.g. Chi et al. (2005) and Aneziris et al. (2008). Saurin and Guimaraes (2008) conducted ergonomic assessment of suspended scaffolds. Chi et al. (2009) also conducted an in-depth accident analysis of electrical fatalities in the construction industry. Beavers et al. (2009) analyzed the steel erection fatalities in the Construction Industry. Further insights were gained on the root causes of the 'struck-by' injuries and prevention against such kind of accidents (Hinze et al., 2005). Studies were also conducted to concentrate on the equipment involved accidents actuating automatic technology to improve construction safety in a proactive real-time mode (Teizer et al., 2010). Hon et al. (2010) conducted a research to demonstrate causes of accidents in repair, maintenance, alteration and addition work in Hong Kong. Lipscomb et al. (2010) analysed 
non-fatal contact injuries among workers in the construction industry treated in U.S. emergency departments. Fung et al. (2010) developed a risk assessment model for assessing risk levels to deal with project safety and risk assessment. Mitropoulos and Namboodiri (2010) used the task demand assessment (TDA) to measure the safety risk of construction activities and analyze how changes in operation parameters could affect the potential for accidents.

Furthermore, from an integral perspective of accidents, some existing studies have been carried out to identify and analyze the causes of safety hazards and risks, in order to prevent fatal and injury accidents on construction sites. Cheng et al. (2010) investigated the characteristic factors responsible for occupational accident occurrence for small construction enterprises in Taiwan. Aneziris et al. (2010) demonstrated the quantification of occupational risk of a highway tunnel construction.

Moreover, accident investigation methods and near miss accidents on construction sites are attached importance to. A new method for accident investigations was presented based on the concept of safety function (Harms-Ringdahl, 2009). Katsakiori et al. (2009) developed an evaluation of accident investigation methods in terms of their alignment with accident causation models. Hatipkarasulu (2010) used the accident investigation reports to categorize project types and presented project level analysis of 350 fatal accidents for special trade contractors. Wu et al. (2010a) developed an investigative tool to derive information of accident precursors and near miss accidents from accident databases on construction sites. Cambraia et al. (2010) conducted a case study in the construction industry concerning identification, analysis and dissemination of information on near miss accidents. Wu et al. (2010b) analyzed and verified the autonomous information requirement of near miss accidents and investigated the feasibility to fulfil these 
requirements.

In the meantime, there have been studies considering safety attitude, safety culture and safety climate (Fung et al., 2005; Fang et al., 2006; Chinda and Mohamed, 2008). Kines et al. (2010) carried out a prepost intervention-control design to test the effect of increasing leader-based on-site verbal safety communication on the level of safety and safety climate at construction sites. Many researchers emphasized the importance of designing for safety issues at an early stage (Weinstein et al., 2005; Gambatese et al., 2005; Gambatese et al., 2008).

Nevertheless, little research has been done in both proactively preventive information requirement analysis of struck-by-falling-object accidents and automatic technological solutions to track crucial and controllable objects for proactive prevention. The objective of this paper is to analyze and verify the proactively preventive information requirement of struck-by-falling-object accidents and bring forward an integrated information management system using a Zigbee RFID sensor network to fulfil these requirements. This study would provide a possible approach for tracking struck-by-falling-object accidents based on real-time information and could serve as a foundation for further study.

\section{Methodology}

\subsection{Empirical methods of case study}

Useful information can be provided by the historical analysis of the accidents about the most frequent accidents, their origins and causes (Darbra and Casal, 2004). In order to conduct an integrated analysis of automatic identification requirement of struck-by-falling-object accidents, the historical records in USA from 1990 to 2008 are analyzed. 
The cases used in this research come from the U.S. Department of Occupational Safety and Health Administrative (OSHA). They are in database form, created by the software Microsoft Access. Every case consists of a situational abstract and detailed description of the accident, providing potentially valuable information. Moreover, in order to focus on common and conventional types of construction sites, accident events are limited to residential, commercial building and manufacturing plant in the statistical analysis.

In total, 499 cases of struck-by-falling-object accidents in residential, commercial building and manufacturing plant from 1990 to 2008 are further analyzed. Five researchers are divided into 2 groups to carry out the case study. The frequency of particular type of objects is analyzed based on vast historical accident cases and then the proactively preventive information requirement of struck-by-falling-object accidents is systematically investigated.

\subsection{Zigbee RFID sensor network}

Radio frequency identification (RFID) refers to a branch of automatic identification technologies in which radio frequencies are used to capture and transmit data from a tag, or transponder (Ergen and Akinci, 2007). The basic components of a typical RFID system include: the transponder or the tag, which is a microchip in which a unique serial code is stored and transmitted when necessary via an antenna attached; the RFID reader/interrogator, which is used to retrieve/receive the identify from the tags. RFID technologies feature efficient and low cost solution for identifying and tracking of objects and personnel. They have been adopted in a wide range of applications, such as healthcare (Katz and Rice, 2009), manufacturing (Huang et al., 2007) and food industries (Kelepouris et al., 2007).

Wireless sensor network (WSN) is a self-organized wireless network composed of a large 
number of sensor nodes that interact with the physical world (Li and Liu 2007). It is a type of ad-hoc wireless network composed of a large number of spatially distributed autonomous sensor nodes that interact with the physical world for remote monitoring and control applications. The ZigBee technology, which is built based on the IEEE802.15.4 standard (Baronti et al., 2007), is one of the most popular WSN standards. Its specification is maintained by the ZigBee Alliance which consists of members from both academic and industry (Yang et al., 2007). The ZigBee technology provides a reliable, low cost and easy to deploy wireless sensor network solution.

The development of promising information technologies, such as RFID and WSN has prompted research into their application to construction. Chae and Yoshida (2010) applied RFID technology to prevention of collision accidents with heavy equipment such as hydraulic excavators and cranes. Teizer et al. (2010b) introduced radio frequency remote sensing and actuating technology to improve construction safety by warning or alerting workers-on-foot and equipment operators in a proactive real-time mode once equipment got too close in proximity to unknown or other equipment. Navon and Berkovich (2005) also have developed a model based on automatic, or semiautomatic, data collection for materials management and control. Navon and Sacks (2007) discussed the monitoring automated data collection needs of and potential technologies to satisfy them. Ergen and Akinci (2007) indicated that RFID technology held the potential for enabling automated tracking of components/materials in dynamic and uncontrolled environments. In the construction industry, WSN has been applied in structural health monitoring (Sazonov 2004; Paek et al. 2005; Li and Liu 2007). Furthermore, Jang and Skibniewski (2009) created a framework for integrating the latest innovations in wireless sensor networks that automate tracking and monitoring construction assets using a combination of radio frequency and ultrasound signals. 
After the proactively preventive information requirement analysis of struck-by-falling-object accidents was completed, RFID and WSN were identified as applicable for their proactive prevention. However, based on the literature review and current technical practices, the requirement for the design of new system architecture for an information management system is raised. An integrated information management system is proposed, which can seamlessly accommodate wireless sensors and RFID tags. This new system employs ultrasonic for outdoor and indoor real-time location tracking, adopts RFID for access control as well as storage of safety information about workers, equipment and material, and wireless sensor network for data transmission. All system components are integrated into a Zigbee RFID sensor network architecture that features relatively low cost and fast implementation with a pure wireless network backbone. The demonstration system based on the hybrid RFID sensor network architecture is then illustrated and discussed.

\section{Proactively preventive requirement of struck-by-falling-object accidents}

\subsection{Involving objects}

In summary, 499 cases are categorized into 14 kinds, which include beam and column (65 cases), large mechanical equipment (64 cases), pipe (53 cases), tree (47 cases), tool and small size equipment (46 cases), brick and block (38 cases), plate (35 cases), cable and rebar (17 cases), truss (17 cases), scaffold (15 cases), form (14 cases), decoration materials (13 cases), pole (12 cases) and others (63 cases). Others include the cases that do not describe the specific involving objects detailedly. Each category consists of several involving objects, which are shown in table 1 (a, b) in details. 
Table 1 (a). Category and Frequency of struck-by-falling-object accidents

\begin{tabular}{|c|c|c|c|c|c|}
\hline Category & Objects & Fre. & Category & Objects & Fre. \\
\hline Beam and & steel beam & 31 & Tool and & metal rods & 7 \\
\hline column & wood beam & 4 & Small Size & pipe wrench & 5 \\
\hline \multirow[t]{10}{*}{ (65) } & steel roof beam & 4 & Equipment & C. clamp & 3 \\
\hline & column & 4 & (46) & stone grinding wheel & 3 \\
\hline & swing beam & 3 & & iron/rubbish/mortar bucket & 3 \\
\hline & i-beam & 2 & & transformer & 2 \\
\hline & precast concrete beam & 2 & & welding cylinder & 2 \\
\hline & tie beam & 1 & & metal ladder & 1 \\
\hline & h-beams & 1 & & c.t. cabinets & 1 \\
\hline & bond beam & 1 & & generator & 1 \\
\hline & Double Tee beams & 1 & & welding unit & 1 \\
\hline & Others & 11 & & hammer & 1 \\
\hline Large & crane boom & 34 & & fire box & 1 \\
\hline Mechanical & hoe bucket & 8 & & muck box & 1 \\
\hline Equipment & headache ball & 5 & & auger & 1 \\
\hline \multirow[t]{6}{*}{ (64) } & elevator & 5 & & D. shackle & 1 \\
\hline & concrete bucket & 4 & & wooden ladder & 1 \\
\hline & metal hopper & 3 & & saw & 1 \\
\hline & rock grapple & 1 & & pulley & 1 \\
\hline & aerial lift & 1 & & masonry mortar buggy & 1 \\
\hline & others & 3 & & steel chute & 1 \\
\hline Pipe & metal pipe & 9 & & sign & 1 \\
\hline \multirow[t]{15}{*}{ (53) } & drain pipe & 5 & & Others & 6 \\
\hline & PVC pipe & 3 & Brick and & Concrete block & 16 \\
\hline & butterfly valve & 3 & block & cement block & 2 \\
\hline & drill pipe & 3 & (38) & refractory block & 1 \\
\hline & metal pipe cap & 2 & & stone & 1 \\
\hline & gas pipeline & 2 & & sheet rock & 1 \\
\hline & soil pipe & 1 & & others & 17 \\
\hline & pipe plug & 1 & Plate & metal plate & 10 \\
\hline & reinforced concrete pipe & 1 & (35) & plank & 8 \\
\hline & water main pipe & 1 & & plywood & 4 \\
\hline & conduit & 1 & & concrete slab & 3 \\
\hline & pipe hanger & 1 & & concrete panels & 1 \\
\hline & fiberglass reinforced pipe & 1 & & ceiling panel & 1 \\
\hline & sprinkler pipe & 1 & & oriented strand board & 1 \\
\hline & others & 18 & & shoring panel & 1 \\
\hline Tree & tree trunk/branch & 47 & & roof deck & 1 \\
\hline (47) & & & & Others & 5 \\
\hline
\end{tabular}


Table 1 (b). Category and Frequency of struck-by-falling-object accidents

\begin{tabular}{|c|c|c|c|c|c|}
\hline Category & Objects & Fre. & Category & Objects & Fre. \\
\hline Cable and & cable & 7 & Form & stell or wood formwork & 6 \\
\hline Rebar & steel & 3 & (14) & steel concrete formwork & 3 \\
\hline \multirow[t]{5}{*}{ (17) } & steel piece & 2 & & trench box wall & 2 \\
\hline & steel connector & 1 & & $\begin{array}{l}\text { steel and plywood concrete } \\
\text { form panel }\end{array}$ & 2 \\
\hline & angle iron & 1 & & concrete stringers & 1 \\
\hline & wire rope & 1 & Decoration & metal roof decking & 3 \\
\hline & others & 2 & Materials & roofing paper & 2 \\
\hline Truss & steel truss & 4 & (13) & hardboard roof insulation & 1 \\
\hline \multirow[t]{7}{*}{ (17) } & brace truss & 2 & & fireproofing material & 1 \\
\hline & wooden truss & 1 & & others & 6 \\
\hline & bent truss & 1 & Pole & power/utility pole & 9 \\
\hline & wind brace & 1 & (12) & others & 3 \\
\hline & fly rafters & 1 & Others & wall & 12 \\
\hline & purlin & 1 & (63) & lumber & 10 \\
\hline & Others & 6 & & pile & 9 \\
\hline Scaffold & scaffold board & 4 & & door & 5 \\
\hline \multirow[t]{3}{*}{ (15) } & scaffold bracket & 2 & & platform & 4 \\
\hline & scaffold rail & 2 & & tank & 4 \\
\hline & others & 7 & & others & 19 \\
\hline
\end{tabular}

It is clear to find out that top three high frequency categories are beam and column (13\%), large mechanical equipment (13\%) and pipe (11\%). In the meantime, tree trunk/branch (47 cases), crane boom (34 cases) and steel beam (31 cases) are the top three high frequency kinds of involving objects.

In one of the typical tree trunk/branch cases, the site was a residential construction project and the victim was involved in tree felling operation on the side of a steep hill above a ravine. The victim got his chainsaw caught up in the tree, and called for another saw man to help him. They were cutting into the tree and the tree fell. The victim was struck and fatally injured by the falling tree. In a typical crane boom case, one employee was attempting to dismantle the boom from a truck crane. The boom was approximately 6 feet above ground level when the lower boom pins 
were removed from the boom point section. This employee was under the boom when it fell, and died after being struck. One of the typical steel beam cases involved a 35 year old male who were killed as a result of a 28 foot long, 600 pound steel beam falling approximately 30 feet. The process trying to be accomplished was the rigging of two steel beams approximately 28 feet long each. They were rigged using a multi-lift method. Two iron workers were performing the rigging operations on the ground and one crane operator located in a tower crane approximately 240 feet high. One of the riggers was fatally struck by the bottom beam when the beam disengaged from the choker.

\subsection{Most hazardous operation}

The most hazardous operation is hoisting/lifting, which accounts for $41 \%$ (205 cases) of all 411 cases. The operation of hoisting/lifting includes all the categories of involved objects. The frequency of hoisting/lifting operation accidents in each category is illustrated in table 2.

Table 2. Frequency of hoisting/lifting operation accidents

\begin{tabular}{rccrcr}
\hline \multicolumn{1}{c}{ Category } & Fre. & Pro. & Category & Fre. & Pro. \\
\hline Large Mechanical Equipment (64) & 60 & $94 \%$ & Form (14) & 8 & $57 \%$ \\
Beam and column (65) & 26 & $40 \%$ & Brick and block (38) & 6 & $16 \%$ \\
Tool and Small Size Equipment (46) & 20 & $43 \%$ & Scaffold (15) & 5 & $33 \%$ \\
Plate (35) & 17 & $49 \%$ & Pole (12) & 5 & $42 \%$ \\
Pipe (53) & 14 & $26 \%$ & Decoration Materials (13) & 3 & $23 \%$ \\
Cable and Rebar (17) & 12 & $71 \%$ & Tree (47) & 3 & $6 \%$ \\
Truss (17) & 9 & $53 \%$ & Others (63) & 17 & $27 \%$ \\
\hline
\end{tabular}

In one of the typical hoisting/lifting cases, two ironworkers rigged structural steel beams to be hoisted by a crane from a truck to a storage area. After the beam was secured in a sling with sorting hooks, one of the workers walked under the beam as it was being lifted. The beam became detached from the sling and struck the worker, resulting in his death. 


\subsection{Proactively preventive information requirement}

As far as the precursors are concerned, most cases refer to the real-time information of location. In other words, if the real-time location information of workers and hazardous objects can be obtained, it is feasible to make an early warning when the involved worker is working too close to the hazards. Furthermore, many cases relate to the proactive information of inspection and quality of materials and machine, the information of qualification and training records of men/women, which are defined as the identity information in this paper. Consequently, based on the results of case study, it is argued that $66 \%$ (330 cases) of struck-by-falling-object accidents have the potential to be avoided. Proactively preventive information requirement majorly lies in the real-time information of location and identity.

Besides, the locomotion process and characteristics of objects are also to be considered when designing the information management system. The locomotion process of involving objects can be classified into three modes that are defined as outside-inside-outside, inside-outside and outside-inside, which are recorded as A, B and C respectively. Mode A refers to the objects that are manufactured outside the construction sites, and then are carried into the construction sites, and finally are taken out of the construction sites, such as large mechanical equipment, scaffold and forms. Mode B relates to the objects that are original in the construction sites, and finally are moved out of the construction sites, such as trees. Mode C involves the objects that are manufactured outside the construction sites, then are carried into the construction sites, and finally are kept in the structure or on sites, such as beam and column, Cable and rebar, decoration materials and so on. A detailed analysis of the locomotion modes of involving objects are shown in table 3. 
Table 3. Locomotion modes of objects

\begin{tabular}{|c|c|c|c|c|c|}
\hline Category & Objects & Type & Category & Objects & Type \\
\hline Beam and column & ALL & $\mathrm{C}$ & Tool and & metal rods & A \\
\hline Large Mechanical & ALL & A & Small Size & pipe wrench & A \\
\hline Equipment & & & Equipment & C. clamp & A \\
\hline Pipe & ALL & $\mathrm{C}$ & & stone grinding wheel & A \\
\hline Tree & ALL & B & & iron/rubbish/mortar bucket & A \\
\hline Brick and block & ALL & C & & transformer & $\mathrm{A} / \mathrm{C}$ \\
\hline Cable and Rebar & ALL & $\mathrm{C}$ & & welding cylinder & A \\
\hline Truss & ALL & $\mathrm{C}$ & & metal ladder & A \\
\hline Scaffold & ALL & A & & c.t. cabinets & $\mathrm{C} / \mathrm{A}$ \\
\hline Form & ALL & A & & generator & A \\
\hline Decoration & ALL & $\mathrm{C}$ & & welding unit & A \\
\hline Materials & & & & hammer & A \\
\hline Pole & ALL & $\mathrm{C}$ & & fire box & $\mathrm{C} / \mathrm{A}$ \\
\hline \multirow[t]{10}{*}{ Plate } & metal plate & $\mathrm{C} / \mathrm{A}$ & & muck box & A \\
\hline & plank & A & & auger & A \\
\hline & plywood & $\mathrm{C}$ & & D. shackle & A \\
\hline & concrete slab & C & & wooden ladder & A \\
\hline & concrete panels & $\mathrm{C}$ & & saw & A \\
\hline & ceiling panel & C & & pulley & A \\
\hline & oriented & $\mathrm{C}$ & & masonry mortar buggy & A \\
\hline & board & & & steel chute & A \\
\hline & shoring panel & A & & sign & A \\
\hline & roof deck & $\mathrm{C}$ & & & \\
\hline \multirow[t]{6}{*}{ Others } & wall & $\mathrm{C}$ & & & \\
\hline & lumber & $\mathrm{C} / \mathrm{A}$ & & & \\
\hline & pile & $\mathrm{C}$ & & & \\
\hline & door & C & & & \\
\hline & platform & A & & & \\
\hline & tank & $\mathrm{C} / \mathrm{A}$ & & & \\
\hline
\end{tabular}

\section{Integrated information management system}

According to the result of case study in the previous section, the primary requirements of the on-site Information Management System for Proactive Prevention of Struck-by-falling-object Accidents are the real-time identification and location tracking of on-site objects, which include 
static objects, mobile equipment and human staff. Simultaneously, the information requirement of locomotion process of Mode A, is majorly considered as other modes' information (B and C) can be dealt with together the same system.

\subsection{Real-time identification}

Automatic Identification technologies, or Auto-ID technologies, are the methods for an autonomous system to capture the identification information. Technologies typically considered under the Auto-ID umbrella include IC/swiping cards, bar codes, Radio Frequency Identification (RFID), biometrics, Optical Character Recognition (OCR), smart cards, and voice recognition. Among them, technologies such as IC/swiping cards and biometrics scanning require actual contact between reading and tagging objects to retrieve information. While most of the other technologies, such as the bar codes, optical Character Recognition, smart cards and voice recognition, all requires a near field presentation of the tagging objects to a reading device. Those features limited the applicability of those technologies for our construction site information management system as they are designed to capture identification information only at certain reading point rather than providing real-time identification information.

RFID is one of the few Auto-ID technologies that have the potential of supporting real-time identification capture. It is a generic term for technologies that use radio waves to automatically identify people or objects (Ergen and Akinci, 2007). The basic components of a typical RFID system include: the tag, the reader and the server. The tag, or called a transponder, is a microchip, in which the unique identification information is stored, with an antenna attached, from which the information is transmitted when necessary; the RFID reader is used to interrogate and capture the identification information sent by tags; the server, usually installed with savant or corresponding 
middleware, is where the readers forward the information to. It is normally a computing device such as a server computer. Compared to the other Auto-ID technologies the RFID system has its own features: instead of typing or scanning the identification code manually, the RFID systems provide us a non-contact data transfer between the tag and the interrogator without the need for obstacle-free, line-of-sight reading; multiple tags can be read simultaneously by a RFID reader, which is known as the batch readability of tags, makes the identification work much more efficient; RFID tags are more reliable while a printed barcode is easily to be broken.

There are generally 3 types of RFID systems depending on the types of tags used, including the active RFID, passive RFID and semi-passive/semi-active RFID systems. Both the passive tags, or called backscatters, and the semi-passive RFID tags do not have own power resource to support an onboard RF transmitter. Instead, they use inductive/propagation coupling to connect with the reader antenna, which means that the passive/semi-passive tags only bounce back the signal emitted by the reader. These passive/semi-passive tags are smaller and cheaper. However, they only have a relatively short reading range and the reader devices have a very high implementation cost. On the other hand, the active RFID tags have onboard transmitters and battery as their power resource. They transmit their Identification information via self-powered RF transmitters and thus can have a wide reading range so that a tag can be continuously interrogated on-site. In our system design, real-time identification information capturing is required. As a result the active RFID is the most suitable option for providing identification information to the information management system.

\subsection{Real-time location tracking}

Most people usually think RFID can provide location information at all the time. But what 
normal passive RFID does is to tell us where an object was the last time it went through a reader, and normal active RFID only tells whether an object is presenting on site. In this case, additional system designs are necessary to support the real-time location tracking function in the information management system.

There are many different types of location tracking technologies. Yang and Yang (2009a) classified the various in-door location tracking technologies in three categories: the non-RF technologies, active-RF technologies and passive-RF technologies. Passive-RF technologies are usually used for special applications such as robot tracking. Although with high tracking accuracy, they have relatively short ranging distance, dense reference point deployment and high implementation cost. Those shortages prevent the passive-RF technologies from being adopted in construction site. On the other hand, the active-RF technologies are the most popular location tracking methods in the market. They have the longest ranging distance and lowest implementation cost. However, the ranging media used are use radio wave which is very sensitive to environment characteristics such as building structure and large furniture. Many of those active-RF systems that use fingerprinting localization mechanism have to be trained during deployment stage to learn their operating environment before being able to achieve usable tracking accuracy. Once the operating environment is changed significantly the system training has to be carried out again. As a result, they are only suitable for location tracking applications with relatively static environment. Construction sites are highly dynamic environment with building structure and position of obstacles changing all the time. Thus the active-RF technologies are not suitable for use in the on-site Information Management System. Non-RF location tracking technologies have acceptable ranging distance, relatively low cost and are not sensitive to 
environment changes. Consequently they are the most suitable technology to be used for our system. The primary non-RF technologies in modern real-time location tracking systems include infrared, ultrasound and video image processing. Among them the ultrasound technology has been proved to be one of the most accurate and reliable ranging methods in indoor environment (Priyantha et al., 2000). A series of further experiments were carried out Jang and Skibniewski (2009) and the results proved the applicability of adopting ultrasound for ranging in real-time location tracking system in the construction site environment. Thus, in our system design the ultrasound is chosen as the localization ranging method.

\section{3 real-time information sharing}

Although the primary identification and location tracking technologies have been chosen, the information captured still remains at the reading point or the mobile point. There has to be an on-site information network platform that accommodates all the devices and transmits the real-time information back to the central server for processing. The most common on-site local network platforms for normal building environment are the LAN/Ethernet (IEEE802.3) and WLAN (IEEE802.11). Both of them are relatively mature technologies and can be easily configured into an IP based network. However, construction sites are dynamic environment; the on-site information management system is not deployed as a permanent system and will operate only during the construction stage. It will be costly and inefficient to adopt the LAN/Ethernet (IEEE802.3) that requires running network cable for all devices in the system. The WLAN (IEEE802.11) is a popular solution for terminal devices to get wireless network access. However, the WLAN standard is designed for hi-speed data network access. This results in a higher level of both device cost and energy consumption. Actually, the devices in our system will transmit only 
the identification and location information that does not require high speed network transmission; while at the same time, they need to achieve reasonable battery life with only on-board power. In this case, those features of WLAN make it less favorable for tracking the mobile objects in our system. Moreover, the terminal devices using WLAN accesses network via the Access Point (AP) devices deployed all over the operation site. Those APs are linked together with the network routers and server with network cables, which puts the WLAN standard back to a cabled network structure in its backbone.

As an attempt to address the limitation of cable running, the Wireless Sensor Network (WSN) is becoming one of the focusing technologies in the last decade as a low cost and low data-rate solution for monitoring and control applications. A typical WSN usually features a multi-hop mesh network topology that provides a flexible and purely wireless/cable-less network backbone. Thus it provides significantly higher flexibility for using in the highly dynamic and flexible environment featured in construction sites.

Although having the terminology 'sensor' in the full name, the area of WSN applications can be extended beyond its original designed purpose of transmitting sensor information. It has been developed as a low-profile data network technology that links almost all types of low level data sources. More particularly for linking RFID devices over WSN, the similarities in hardware structure of sensor network node/router and active RFID tag/reader have provided the possibility of combining the two technologies. In the work of Yang and Yang (2007), the feasibility of using sensor network nodes to perform active RFID functionalities have been explored and affirmed. With even higher level functionality and more completed communication stack comparing to active RFID tags, the WSN network nodes are capable of being used as active tags, but with 
further extended network features. In this case, the WSN is considered the most suitable networking technology for our on-site information management system design.

The WSN standard used in our system design is the ZigBee technology, which is one of the most popular WSN technologies available. ZigBee is a network and application level specification built based on the IEEE802.15.4 standard, which specifies the MAC and physic level. The specification is provided and maintained by ZigBee Alliance, an association whose members are leading companies in the industrial. A typical ZigBee network consists of a coordinator device, some router devices and many end devices. The coordinator device is responsible for establishing and managing the network resources. Router devices construct the backbone of the network and usually link together in a mesh topology. The end devices are the lowest profile devices that are linked into the network by communicating to one of the router devices as their parent node. ZigBee technology dedicates to enabling reliable, cost-effective, low-power, wirelessly networked monitoring and control products. The data rate can be supported up to $250 \mathrm{kbps}$ which is enough for transmitting simple identification and location information. It supports star, tree and mesh network topologies, and is able to accommodate up to 65,535 network nodes in a single network instance. ZigBee stack can be used to route messages reliably and provide strong in-built security measures. Moreover, ZigBee is a low power technology. Two AA batteries can support ZigBee device to work over years (Kinney, 2003). Compared with Wi-Fi and Bluetooth, ZigBee has unbeatable preponderance at low data-rate market.

\subsection{System structure}

Based on the discussion above, we present our system structure design for the on-site information management system for proactive prevention of Struck-by-falling-object accidents on 
construction sites. The structure is illustrated in Figure 1.



Figure 1. System structure

In this integrated architecture all data communications inside the network are expected to be supported by the ZigBee technology. The “Active RFID tag as a sensor” concept (Yang and Yang, 2007) is adopted in our system design. The components that construct a wireless sensor node are similar to those which an active RFID tag is constructed of: a sensor node is self-powered and transmits sensing information to a router, while an active RFID tag transmits identification information to the active RFID readers using the same components. If we consider identification information as a special type of sensing information, the active tags can thus be deemed as a “sensor" device with extended concept. In this case, some WSN routers will be programmed to function as virtual active RFID readers, which are able to read the wireless sensor nodes with ID information like an active RFID system. All the routers and virtual active RFID readers are linked by the sensor network protocol to connect with the central server via a multi-hop communication path constructed by other readers and router devices. Although traditional Active RFID can be involved if their reader can be made to be compatible with the ZigBee network protocols, using 
ZigBee nodes directly to undertake the identification task is more simple and straight forward.

Ultrasound ranging is chosen for location tracking function. With ultrasound transceivers deployed on the tracked objects (workers, equipment, etc.) and in the working area respectively, ranging from the moving objects to specific fixed reference points will be available, from which the location of the objects can be calculated. In our scenario, each tracked object is equipped with ultrasound transceivers to listen to the reference point nodes transceivers. The reference point nodes should be deployed over the site with a density high enough to ensure that a track object transceiver can hear at least three reference node transceivers at any position. The ranging result to all the reference nodes together with the tracked objects' identification information are sent regularly to the central server via the standard ZigBee communication network. Benefiting from the flexibility of the sensor network architecture, the sensor nodes, active RFID readers can be made into system compatible, plug and play modules. This can simplify the design and implementation of the final system for each different construction site.

The central server is connected via serial port to a ZigBee adaptor, which enables the server to act as a network node in the network and to retrieve all the information. The identification and location tracking information are pushed into database and are processed by the server application. The data processing includes calculating absolute location of objects based on ranging information, server application rendering and alarm generation. Specific policies are to be specified in the server application for alarm generations. When an alarm event is generated, it is immediately sent back to the corresponding nodes to trigger on-board warnings, such as flashing light or sound warnings.

\subsection{Demonstration system}


We developed a simple demonstration system using the Jennic JN51xx series ZigBee sensor network development kit. One module was programmed as the coordinator and was also connected to the central server via serial connection to serve as the ZigBee adaptor to retrieve messages from the other nodes. Three more modules integrated with ultrasound transceivers were deployed at fixed positions in our laboratory which has a typical in-building environment. These three fixed nodes are programmed to be the ZigBee router nodes, with the on-board ultrasound transceiver transmitting ultrasound beacon periodically. They are considered as having multiple roles in the system, carrying out the functionalities of ultrasound location reference points, network package routers and active RFID readers in construction site. The last module was also equipped with ultrasound transceiver, but was programmed to be an end device in the ZigBee network with the on-board ultrasound transceiver continuously listening to the reference beacon signals. This node was considered to be the active RFID tag attached on the objects to be tracked.

Figure 2 shows the system deployment of this experiment. The coordinator establishes the network, followed by the joining of five fixed router nodes and two end devices making the network a typical ZigBee monitoring system. The fixed router nodes transmit ultrasound beacons together with their node ID, which were successfully captured by the end device's ultrasound transceiver. The end devices then pack that information with their own identification information in a single message and sent it to the central server using standard ZigBee network link. The information was received by the server via the adaptor node, and could then be used by triangulation localization algorithms to calculate the exact location of the mobile object. This demonstration system has clearly shown the feasibility of our system structure and hardware design and implementation. 


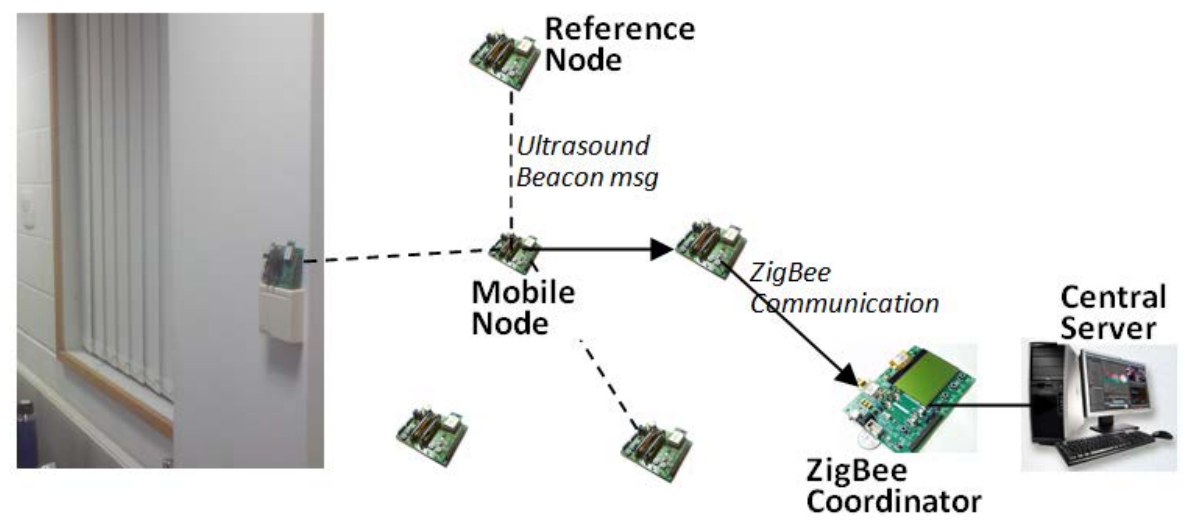

Figure 2. Demonstration system

\section{Discussion and conclusion}

Fatal accidents on construction sites are just the tip of an iceberg because a large number of near-miss accidents exist and constitute the portion of under-water surface (Heinrich, 1959). It was estimated that $90.9 \%$ of all accidents produced no injuries, while $8.8 \%$ resulted in minor injuries and only 0.3\% caused major injuries (Heinrich, 1959; Navon and Berkovich, 2005). Thus, involved objects that have only one case record are also investigated (in table 1) in order to offers the great potential of improving safety by concentrating on hazardous incidents.

As the description of some cases did not include the specific involving objects in detail, which led to the inconvenience of case study and limited a deeper analysis. Thus, it is also suggested that the investigation process could record and provide particular information about involving objects in the future.

The compatibility of various RFID devices to WSN network and the feasibility of using WSN protocol to performance active RFID service have been demonstrated in previous work (Yang et al., 2007; Yang and Yang, 2007). Our work also demonstrated the capability of such architecture to be further extended for real-time tracking service (Yang and Yang, 2009a, 2009b). 
Struck-by-falling-object accidents are not paid adequate attention to though they are of great importance on construction sites. Little research has been done in both proactively preventive information requirement analysis of struck-by-falling-object accidents and automatic technological solutions to track crucial and controllable objects for proactive prevention. In summary, 499 cases have been investigated and categorized into 14 kinds including beam and column, large mechanical equipment, pipe, tree, tool and small size equipment, brick and block, plate, cable and rebar, truss, scaffold, form, decoration materials, pole and others. Top three high frequency categories are beam and column, large mechanical equipment and pipe. In the meantime, tree trunk/branch, crane boom and steel beam are the top three high frequency kinds of involving objects. Furthermore, the most hazardous operation has been found out to be hoisting/lifting, which accounts for $41 \%$ of all cases, which includes all the categories of involved objects. It is argued that $66 \%$ of struck-by-falling-object accidents have the potential to be avoided. Then, this paper has analyzed and verified the proactively preventive information requirement of struck-by-falling-object accidents and brought forward an integrated information management system. Proactively preventive information requirement majorly lies in the real-time information of location and identity. An integrated information management system has been proposed, which employs ultrasonic for outdoor and indoor real-time location tracking, adopts RFID for access control as well as storage of safety information about workers, equipment and material, and wireless sensor network for data transmission. All system components are integrated into a Zigbee RFID sensor network architecture that features relatively low cost and fast implementation with a pure wireless network backbone. The demonstration system based on the hybrid RFID sensor network architecture has also been illustrated and discussed. This study would provide a possible 
approach for tracking struck-by-falling-object accidents based on real-time information for proactive prevention and could serve as a foundation for further study.

\section{Acknowledgements}

The research work for this paper is funded by the National Natural Science Foundation of China

(Grant No. 51008073 and 50878049).

\section{References}

Al-Humaidi1, H. M., Tan, F. H., 2010. Construction Safety in Kuwait. Journal of Performance of Constructed Facilities, 24, 1: 70-77.

Aneziris, O.N., Papazoglou, I.A., Baksteen, H., Mud, M., Ale, B.J., Bellamy, L.J., Hale, A.R., Bloemhoff, A., Post, J., Oh, J., 2008. Quantified risk assessment for fall from height. Safety Science, 46: 198-220.

Aneziris, O. N., Papazoglou, I. A., Kallianiotis, D., 2010. Occupational risk of tunneling construction. Safety Science, 48(8): 964-972.

Baronti, P., Pillai, P., Chook, V.W.C., Chessa, S., Gotta, A., Hu, Y.F., 2007. Wireless sensor networks: A survey on the state of the art and the 802.15.4 and ZigBee standards. Computer Communications 30(7), 1655-1695

Beavers, J.E., Moore, J. R., Schriver, W.R., 2009. Steel erection fatalities in the construction industry. Journal of Construction Engineering and Management, 135(3), 227-234.

Cambraia, F. B., Saurin, T. A., Formoso, C. T., 2010. Identification, analysis and dissemination of information on near misses: A case study in the construction industry. Safety Science, 48(1): 91-99.

Chae, S., Yoshida, T., 2010. Application of RFID technology to prevention of collision accident with heavy equipment. Automation in Construction, 19: 368-374.

Cheng, C. W., Leu, S. S., Lin, C. C., Fan, C., 2010. Characteristic analysis of occupational accidents at small construction enterprises. Safety Science,2010, 48(6):698-707

Chi, C.F., Chang, T.C., Ting, H.I., 2005. Accident patterns and prevention measures for fatal occupational falls in the construction industry. Applied Ergonomics 36: 391-400.

Chi, C.F., Yang, C.C., Chen, Z.L., 2009. In-depth accident analysis of electrical fatalities in the construction industry. International Journal of Industrial Ergonomics, 39(4): 635-644.

Chinda, T., Mohamed, S., 2008. Structural equation model of construction safety culture. Engineering, Construction and Architectural Management, 15 (2), 114-131.

Darbra, R.M., Casal, J., 2004. Historical analysis of accidents in seaports. Safety Science 42, 
Ergen, E., Akinci, B., 2007. An Overview of Approaches for Utilizing RFID in Construction Industry. Proceedings of RFID Eurasia, 1st Annual, 1-5.

Katz, J.E., Rice, R.E., 2009. Public views of mobile medical devices and services: A US national survey of consumer sentiments towards RFID healthcare technology. International Journal of Medical Informatics 78(2), 104-114.

Fang, D.P., Chen, Y., Wong, L., 2006. Safety climate in construction industry: a case study in Hong Kong. Journal of Construction Engineering and Management, 132(6), 573-584.

Fung, I. W. H., Tam, V. W. Y., Lo, T. Y., Lu, L. L. H., 2010. Developing a Risk Assessment Model for construction safety. International Journal of Project management, 28(6): 593-600.

Fung, I.W.H., Tam, C.M., Tung, K.C.F., Man, A.S.K., 2005. Safety cultural divergences among management, supervisory and worker groups in Hong Kong construction industry. International Journal of Project Management, 23, 504-512.

Gambatese, J.A., Behm, M., Hinze, J.W., 2005. Viability of designing for construction worker safety. Journal of Construction Engineering and Management, 131(9), 1029-1036.

Gambatese, J.A., Behm, M., Rajendran, S., 2008. Design’s role in construction accident causality and prevention: Perspectives from an expert panel. Safety Science, 46, 675-691.

Goh, Y. M. and Love, P. E.D., 2010. Adequacy of personal fall arrest energy absorbers in relation to heavy workers. Safety Science, 2010, 48(6): 747-754.

Harms-Ringdahl, L, 2009. Analysis of safety functions and barriers in accidents. Safety Science, 47, 353-363.

Hatipkarasulu, Y., 2010. Project level analysis of special trade contractor fatalities using accident investigation reports. Journal of Safety Research, 41: 451-457.

Heinrich,H.W., 1959. Industrial Accident Prevention. McGRAW HILL Book Company.

Hinze, J., Pedersen, C., Fredley, J., 1998. Identifying root causes of construction injuries, Journal of Construction Engineering and Management, 124(1): 67-71.

Hinze, J., Huang, X.Y., Terry, L., 2005. The nature of struck-by accidents. Journal of Construction Engineering and Management, 131(2), 262-268.

Hon, C. K.H., Chan, A. P. C., Wong, F. K.W., 2010. An analysis for the causes of accidents of repair, maintenance, alteration and addition works in Hong Kong. Safety Science, 48(7): 894-901.

Huang,G.Q.,Zhang,Y.F.,Jiang, P.Y., 2007. RFID-based wireless manufacturing for walking-worker assembly islands with fixed-position layouts. Robotics and Computer-Integrated Manufacturing 23(4), 469-477.

Jang, W. K., Skibniewski, M. J., 2009. Embedded system for construction asset tracking combining radio and ultrasound signals. Journal of Computing in Civil Engineering 23 (4), 221-229.

Katsakiori, P., Sakellaropoulos, G., Manatakis E, 2009. Towards an evaluation of accident investigation methods in terms of their alignment with accident causation models. Safety Science, 47, 1007-1015.

Katz, J.E., Rice, R.E., 2009. Public views of mobile medical devices and services: A US national 
survey of consumer sentiments towards RFID healthcare technology. International Journal of Medical Informatics 78(2), 104-114.

Kelepouris, T., Pramatari, K., Doukidis, G., 2007. RFID-enabled traceability in the food supply chain. Industrial Management \& Data Systems 107(2), 183-200.

Kines, P., Andersen, L. P. S., Spangenberg, S., Mikkelsen, K. L., Dyreborg, J., Zohar, D., 2010. Improving construction site safety through leader-based verbal safety communication. Journal of Safety Research, 41: 399-406.

Kinney, P. 2003. Zigbee Technology: Wireless Control that Simply Works. Communications Design Conference.

Li, M., Liu, Y., 2007. Underground structure monitoring with wireless sensor networks. Proceedings of conference on Information processing in sensor networks: 69-78.

Lipscomb, H. J., Schoenfisch, A. L., Shishlov, K. S., 2010. Non-fatal contact injuries among workers in the construction industry treated in U.S. emergency departments, 1998-2005. Journal of Safety Research, 41(3):191-195.

McCann, M., 2006. Heavy equipment and truck-related deaths on excavation work sites. Journal of Safety Research, 37, 5: 511-517.

Mitropoulos, P., Namboodiri M., 2010. New Method for Measuring the Safety Risk of Construction Activities: Task Demand Assessment. Journal of Construction Engineering and Management, 137(1): 30-38

Navon, R., Berkovich, O., 2005. Development and on-site evaluation of an automated materials management and control model, Journal of Construction Engineering and Management, 131(12): 1328-1336.

Navon, R., Sacks, R., 2007. Assessing research issues in Automated Project Performance Control (APPC). Automation in Construction, 16: $474-484$.

Paek, J., Chintalapudi, K., Govindan, R., Caffrey, J., Masri, S., 2005. A wireless sensor network for structural health monitoring: performance and experience. Proceedings of Embedded Networked Sensors (EmNetS-II): 1-10.

Priyantha, N.B., Chakraborty, A., Balakrishnan, H. 2000. The Cricket Location-Support System, ACM Press, Boston, 2000.

Saurin, T.A., Guimaraes, L.B.D.M., 2008. Ergonomic assessment of suspended scaffolds. International Journal of Industrial Ergonomics, 38, 238 - 246.

Sazonov, E., 2004. Wireless intelligent sensor network for autonomous structural health monitoring. Proceedings of the Society of Photo-optical Instrumentation Engineers (SPIE), 5384: 305-314.

Teizer, J., Allread, B. S., Fullerton, C. E., Hinze, J., 2010. Autonomous pro-active real-time construction worker and equipment operator proximity safety alert system. Automation in Construction, 19: 630-640.

Teizer, J., Allread, B. S., Fullerton, C. E., Hinze, J., 2010b. Autonomous pro-active real-time construction worker and equipment operator proximity safety alert system. Automation in Construction, 19: 630-640.

Thomas, D., 2006. What is killing UK construction workers? Structural Engineer, 84(22): 13-14. 
Wu, W., Yang, H., Chew, D., Yang, S., Gibb, A., Li., Q., 2010. Towards an autonomous real-time tracking system of near-miss accidents on construction sites. Automation in Construction, 19(2): 134-141.

Weinstein, M., Gambatese, J., Hecker, S., 2005. Can design improve construction safety?: assessing the impact of a vollaborative dafety-in-fesign process. Journal of Construction Engineering and Management, 131(10), 1125-1134.

Wu, W., Gibb, A., Li, Q., 2010a. Accident precursors and near misses on construction sites: An investigative tool to derive information from accident databases. Safety Science 48(7), 845-858.

Yang, H.J., Yang, S.H. 2007. RFID sensor network: network architectures to integrate RFID, sensor and WSN, Measurement and Control 40 (2): 56 - 59.

Yang, H., Yang, S. 2009a. Indoor Localization Systems - Tracking objects and personnel with sensors, wireless network and RFID. Measurement and Control, volume 42, 18-23, 2009

Yang H, Yang SH. 2009b. Indoor localization systems - tracking objects and personnel with sensors, wireless networks and RFID. The Journal of the Institute of Measurement and Control, 42(1):18-23.

Zeng, S., Powers, J. R., Newbraugh, B. H., 2010. Effectiveness of a worker-worn electric-field sensor to detect power-line proximity and electrical-contact. Journal of Safety Research, 41(3): 229-239. 